coronary artery disease in men. This may partly explain differences between individuals in the development of coronary artery disease. Of the three other polymorphisms in this gene, the most extensively studied, intronic PvuII polymorphism, showed no association with coronary artery stenosis as measured by angiography. ${ }^{5}$ Although the biochemical evidence is presently lacking, we speculate that carriers of the long repeat variants have lower expression of the oestrogen receptor gene and benefit less from the cardiovascular protective effect of oestrogen receptors.

We thank Outi Lumme and Mervi Niittylahti for their skilful technical assistance, Seppo Tyynelä for planimetric measurements, and Markus Perola for DNA isolation.

Contributors: TAK carried out the genotyping, did most statistical analyses, and wrote the first draft of the article. PL was responsible for statistical analyses. AP was involved in sample and data collection. TL participated in writing the article. PJK initiated the study, was involved in sample and data collection, and is the guarantor for the study. All authors helped in completing the article.
Funding: This work was funded by the Medical Research Fund of Tampere University Hospital, the Yrjö Jahnsson Foundation, the Finnish Foundation of Alcohol Research, and the Tampere Regional Fund of the Finnish Cultural Foundation. Competing interests: None declared.

1 Losordo DW, Kearney M, Kim EA, Jekanowski J, Isner JM. Variable expression of the estrogen receptor in normal and atherosclerotic coronary arteries of premenopausal women. Circulation 1994;8:1501-10.

2 Sano M, Inoue S, Hosoi T, Ouchi Y, Emi M, Shiraki M, et al. Association of estrogen receptor dinucleotide repeat polymorphism with osteoporosis. Biochem Biophys Res Commun 1995;217:378-83.

3 Mikkelsson J, Perola M, Laippala P, Savolainen V, Pajarinen J, Lalu K, et al. Glycoprotein IIIa PIA polymorphism associates with progression of coronary artery disease and with myocardial infarction in an autopsy series of middle-aged men who died suddenly. Arterioscler Thromb Vasc Biol 1999;19:2573-8

4 Kunnas TA, Holmberg-Marttila D, Karhunen PJ. Analysis of estrogen receptor dinucleotide polymorphism by capillary gel electrophoresis with a population genetic study in 180 Finns. Hum Hered 1999;49:142-5.

5 Matsubara Y, Murata M, Kawano K, Koichi Z, Zama T, Aoki N. Genotype distribution of estrogen receptor polymorphism in men and postmenopausal women from healthy and coronary populations and its relation to serum lipid levels. Arterioscler Thromb Vasc Biol 1997;17:3006-12.

(Accepted 14 April 2000)

\title{
Early neonatal mortality, asphyxia related deaths, and timing of low risk births in Hesse, Germany, 1990-8: observational study
}

\author{
Günther Heller, Björn Misselwitz, Stephan Schmidt
}

Institute of Medical Sociology and Social Medicine, Medical Centre of Methodology and Health Research, Philipps-University of Marburg, Medical School, D 35033 Marburg, Germany Günther Heller assistant professor

Department of Obstetrics, Centre of Gynaecology and Obstetrics,

Philipps-University of Marburg

Stephan Schmidt professor of gynaecology and obstetrics

Institute of Quality Assurance Hesse, D 65760 Eschborn, Germany

Björn Misselwitz public health researcher

Correspondence to: G Heller hellerg@mailer. uni-marburg.de

BMJ 2000;321:274-5
A higher neonatal mortality related to intrapartum events during the night has been reported in Great Britain. ${ }^{12}$ We investigated whether the time of birth affects early neonatal mortality or deaths related to asphyxia in low risk births.

\section{Participants, methods, and results}

Data from the perinatal birth register of the federal state of Hesse, Germany, 1990-8, were used (www.medqs-hessen.de). The register comprises detailed information about all infants born in birth clinics (more than $95 \%$ of all births in Hesse); about the mother, including the pregnancy; and about the delivery, as documented by the obstetrician in charge of the birth, using an evaluated standardised questionnaire comprising 67 items. ${ }^{3}$ Detailed information is available about the child's morbidity and reasons for death coded in 40 predefined categories adapted from ICD-9 (international classification of diseases, 9 th revision).

Outcome events were deaths during labour or within the first seven days of life (early neonatal deaths) and asphyxia related deaths during the same period.

Early neonatal mortality and timing of birth in low risk births in Hesse, Germany, 1990-8

\begin{tabular}{|c|c|c|c|c|c|c|}
\hline & \multirow[b]{2}{*}{$\begin{array}{c}\text { Births }(n=380 \\
930)\end{array}$} & \multicolumn{3}{|c|}{ Early neonatal deaths } & \multicolumn{2}{|c|}{ Asphyxia related deaths $\dagger$} \\
\hline & & No $(n=57)$ & Relative risk* $(95 \% \mathrm{Cl})$ & $\begin{array}{l}\text { Median time of } \\
\text { birth }\end{array}$ & No $(n=21)$ & Relative risk* $(95 \% \mathrm{Cl})$ \\
\hline Night time births & 148991 & 31 & 1.86 (1.10 to 3.13$)$ & $135 \mathrm{am}$ & 15 & 3.89 (1.51 to 10.03$)$ \\
\hline Daytime births & 231939 & 26 & & $1524 \mathrm{pm}$ & 6 & \\
\hline
\end{tabular}

*Births at night $v$ births during the day.

tAsphyxia given as cause of death for infants who died during labour or in the first seven days of life.
Completeness of the record of all early neonatal deaths was validated by comparison with corresponding Hesse. $^{4}$

To control for the effects of planned births with respect to the time of birth we excluded antepartum deaths, caesarean sections, infants born before the 37 th week of gestation, and infants with congenital malformations or hereditary metabolic diseases. Those births occurring between $9 \mathrm{pm}$ and 659 am were defined as night time births. Otherwise births were assumed to have taken place during the day.

Relative risks and 95\% confidence intervals were calculated to assess the effect of night and day on death rates. A total of 380930 births met the criteria for inclusion. Fifty seven early neonatal deaths were observed, reflecting the low mortality risk of these selected births. Babies born at night were almost twice as likely to die as babies born during the day (relative risk $=1.86 ; 95 \%$ confidence interval 1.10 to 3.13 ). For deaths related to asphyxia an even more pronounced relation was observed $(3.89 ; 1.51$ to 10.03 ; table). death rates as reported by the statistical office of 


\section{Comment}

Our results confirm a higher early neonatal mortality in low risk babies born at night. This may be a result of staff's increased physical and mental fatigue during the night, when doctors in charge, at least in Germany, have usually worked through a complete day shift. Overreliance on less experienced staff may be another important reason for the higher risk of early neonatal death during the night. These phenomena are not specific to the NHS or the British population. Better designed shifts, resulting in shorter working hours or decreased workload with greater supervision by experienced staff at night, should be considered to reduce early neonatal mortality during the night.

Although our analyses are consistent with previously reported British results, some differences should be considered. ${ }^{12}$ We used slightly different definitions of night and day because the hours of day shifts are different in Germany. Applying the time categorisation of the British studies yielded almost identical results. Because of the nature of our database only deaths occurring during labour or in the first seven days of life could be traced. There was some concern that babies born during the day are more likely to be preterm or high risk babies who have had induced births. We therefore restricted our study population rigorously. The assumption that a death was related to asphyxia relied solely on the obstetrician's documentation of morbidity and reasons for death, which could be prone to error. Nevertheless, a higher early neonatal mortality in general and a higher mortality related to asphyxia were seen. Additionally, for each deceased child each author reviewed all the information available from the register's database for other potential confounding factors. No alternative explanations for the reported relationship were found.

We thank Christiane Gasse for revising the manuscript and helpful comments.

Contributors: GH had the idea for the paper, performed statistical analysis, wrote the paper, and is the study guarantor. BM gave access to data, participated in performing statistical analysis, and commented on the draft. SS helped to write the paper. All authors reviewed the database for each deceased child.

Funding: None.

Competing interests: None declared.

1 Stewart JH, Andrews J, Cartlidge PHT. Numbers of deaths related to intrapartum asphyxia and timing of birth in all Wales perinatal survey, 1993-5. BMJ 1998;316:657-60.

2 Chalmers JWT, Shanks E, Paterson S, McInneny K, Baird D, Penney G. Scottish data on intrapartum related deaths are in same direction as Welsh data. BMJ 1998;317:539.

3 Künzel W. The birth survey in Germany-education and quality control in perinatology. Eur J Obstet Gynecol Reprod Biol 1994;54:13-20.

4 Hofacker G. Säuglingssterblichkeit 1998. Staat und Wirtschaft in Hessen 1999;11:326-9.

(Accepted 17 April 2000)

\section{Correction}

Systematic reviews and meta-analyses on treatment of asthma: critical evaluation

Several errors occurred in table 2 of this paper by Jadad et al (26 February, pp 527-40). Under the heading "Was bias in the selection of the studies avoided?" the number for "all" should be 14/30, not 15/30; under "Were the findings of the relevant studies combined appropriately?" the number for "all" should be 22/26, not 24/26; and under: "Were the conclusions made by the author(s) supported by the data provided?" the number for "peer reviewed journals" should be $14 / 38$, not $14 / 14$. The $\mathrm{P}$ values are the same.

\section{Drug points}

\section{Atrial fibrillation associated with sumatriptan}

D R Morgan, M Trimble, G E McVeigh, General Medicine Department, Belfast City Hospital, Belfast BT9 7AB

A 34 year old man with a history of migraine presented with palpitations after taking sumatriptan by nasal spray for a severe headache. Examination was unremarkable apart from atrial fibrillation, with a ventricular rate of $130 \mathrm{beats} / \mathrm{min}$. He recalled having had a fast irregular pulse after taking sumatriptan previously, and this was confirmed from his case notes. He reverted to sinus rhythm spontaneously within 12 hours of admission. Thyroid function tests and a transthoracic echocardiogram gave normal results. Exercise stress testing showed no abnormalities.

Sumatriptan is a 5-hydroxytryptanine agonist active at 5-hyroxytryptanine $1 \mathrm{~B}$ and $1 \mathrm{D}$ receptors. Chest tightness and pain are reported in up to $15 \%$ of patients and are presumed to be due to vasoconstriction of the coronary arteries. $^{1} \quad$ At therapeutic plasma concentrations, sumatriptan does not reduce myocardial perfusion in healthy migraineurs. ${ }^{2}$ Myocardial infarction has, however, been reported as a consequence of sumatriptan treatment for migraine and its use is contraindicated in patients with ischaemic heart disease. ${ }^{1}$

Sumatriptan is the drug most frequently reported to cause chest pain. ${ }^{3}$ Atrial fibrillation associated with sumatriptan is uncommon. The Committee on Safety of Medicines has received six reports of atrial fibrillation associated with sumatriptan, which accords with data from the manufacturer. Naratriptan has been associated with one episode of atrial fibrillation. The Committee on Safety of Medicines has received no reports of arrhythmias with rizatriptan, but it has been associated with tachycardia and chest pain (data from manufacturers).

In this patient's case there was evidence of rechallenge, implicating sumatriptan as the cause of the atrial fibrillation, irregular tachycardia having been previously documented after sumatriptan use. The mechanism causing atrial fibrillation is uncertain. In this patient underlying coronary insufficiency seems unlikely. Sumatriptan has been shown to be without inherent tachycardic effect in in vivo preparations of denervated cat heart. ${ }^{4}$ Therefore, we suggest that myocardial ischaemia secondary to coronary vasospasm could be a trigger for atrial fibrillation.

Competing interests: None declared.

1 VanDenBrink AM, Reekers M, Bax WA, Ferrari MD, Saxena PR. Coronary side-effect potential of current and prospective antimigraine drugs. Circulation 1998;95:25-30.

2 Lewis PJ, Barrington SF, Marsden PK, Maisey MN, Lewis LD. A study of the effects of sumatriptan on myocardial perfusion in healthy female migraineurs using ${ }^{13} \mathrm{NH}_{3}$ positron emission tomography. Neurology 1997:48:1542-50

3 Ottervanger JP, Wilson JHP, Stricker BHC. Drug-induced myocardial infarction. Reports to a national centre and review of the literature. Eur Clin Pharmacol 1997;53:105-10.

4 Villalon CM, Heiligers JPC, Centurion D, De Vries P, Saxena PR. Characterization of putative 5-HT7 receptors mediating tachycardia in the cat. Br J Pharmacol 1997;121:1187-9. 